\title{
Morphological And Morphometrical Aspects of The Auditory Ossicles In Roe Deer (Capreolus \\ Capreolus)
}

\section{Martonos Cristian}

University of Agricultural Sciences and Veterinary Medicine Cluj-Napoca

Alexandru Gudea ( $\nabla$ alexandru.gudea@usamvcluj.ro )

University of Agricultural Sciences and Veterinary Medicine Cluj-Napoca https://orcid.org/0000-00033884-9686

\section{D’Amico Gianluca}

University of Agricultural Sciences and Veterinary Medicine Cluj-Napoca

\section{Stan Florin}

University of Agricultural Sciences and Veterinary Medicine Cluj-Napoca

\section{Short Report}

Keywords: roe-deer, middle ear, ear ossicles, morphology, morphometry

Posted Date: January 28th, 2022

DOI: https://doi.org/10.21203/rs.3.rs-1243120/v1

License: (9) This work is licensed under a Creative Commons Attribution 4.0 International License. Read Full License 


\section{Abstract}

The study provides a series of distinctive aspects of the auditory ossicles alongside comparative morphometric data, bringing facts in respect to morphology and morphofunctionality of the auditory ossicles in this little-studied species. The most important features noted are evident conical shape of muscular process of malleus and triangular aspect of the handle of malleus. For the incus, a short body of the bone and the direct continuation, with no clear distinction as an individualized piece, for the lenticular process. As for the stapes, the clear profiling of the muscular tubercle for the stapedial muscle and elliptic shape of the foot of the stapes is noted. A series of comparative measurements and indices are also calculated in the attempt of profiling differences from the domestic counter species- sheep and goat.

\section{Introduction}

Taxonomically, the roe deer belongs to the Atryodactyla order, Subfamily Capreolinae, genus Capreolus, species Capreolus Capreolus, with more than 55 subspecies. The ear is an important sensory organ, comprising structures that originate from the neural crests, endodermal, mesodermal, and ectodermal layers. Anatomically, the ear consists of three distinctive sectors: the external ear (auris externa), the middle ear (auris media) and the internal ear (auris interna). Placed in the dorsal part of the tympanic cavity (cavum tympany), within the temporal bone, the petrosal part (os temporale, pars petrosa), the assembly of the auditory ossicles (ossicula auditus) play an important role in the sound transmission from the tympanic membrane (membrana tympany) to the internal ear (vestibular fenestra- fenestra vestibuli) (Martonos et al. 2019; Pfaff et al. 2019).

The present study aims to provide morphological and morphometrical data concerning the auditory ossicles. Given the so-called "transitional type" of the ear and the malleus-incus microtype (Péus et al. 2020) for the studied species, special emphasis is given to some correlative facts between mechanical and physical aspects and some of the metrical features of the ear ossicles to the specificity of sound transmission.

\section{Material And Methods}

The biological material was represented by 6 roe deer crania originating from the collection of comparative specimens included in the Anatomy Department's reserve. A bone rongeur was also used to create a small window to allow the approach of the middle ear cavity and the acoustic bone assembly. Ossicles were gently cleansed and prepared for in-depth macroscopical analysis.

Based on the digital images collected (Olympos MTX stereomicroscope and camera), a graphical digital tablet (Wacom Intuos Art \& Touch Small) (Wacom Corporation Intl), Corel Painter Essentials 5 suite (Corel

$\mathrm{Tm}$ ) and ImageJ , a graphical redraw and further measurements of the ossicular assembly were made. Measurements on the auditory ossicles were made in accordance with data suggested by a series of 
authors (Kurtul et al. 2003; Wang and Gan 2016; Gürbüz et al. 2019; Péus et al. 2020) with some adaptations(Mason and Farr 2012) for the functional metric assessment.

\section{Results}

The largest of the ossciles- the malleus (Malleus) is the laterally placed one, connected to the smaller incus (Incus) and then, the most medially placed, the stapes (Stapes).

The Malleus consists of a head (Caput mallei) connected by a neck (Collum mallei) to the handle (Manubrium mallei). The head of the malleus in Capreollus capreollus is ovally-shaped, slightly obliquely placed medio-laterally, cranio-caudally. On its dorso-caudal border, an articular surface (Facies articularis) with a relatively circular shape and somehow divided into 2 distinctive, uneven surfaces is present. The angulation between the 2 surfaces was measured to be approximately 135 degrees. The neck of the malleus is well profiled, obliquely placed in ventro-lateral and caudal direction, slightly flattened, with an overall curly appearance. Its dorsal border is convex while in the distal part slightly concave. The neck has three processes: the anterior process (Processus rostralis) in ventro-cranial direction, the muscular process (Processus muscularis), and the lateral process (Processus lateralis). A thin ossicular lamina that extends in a pointed direction, overpassing the overall shape of the ossicle, imparts the overall shape of a triangular pennant. The conical muscular process detaches from the medial surface of the neck, at the same level as the anterior process is detaching. The lateral process detaches from the lateral surface of the neck, close to the terminal part of this segment, marking the passage to the manubrium. This process has a triangular shape and can be easily identified through the tympanic ring. The last segment- the handle of malleus (Manubrium mallei) continues ventrally. It has an overall tri-faceted process that terminates flattened, pointed, almost rounded distally, exceeding $50 \%$ out of the total length of the malleus.

The incus (Incus) has a body (Corpus incudis) and two crura (Crus breve, Crus longum), the body being the most developed segment of this ossicle. Overall, the ossicle has the shape of a human bicuspid tooth. The body possesses a visible articular process- Processus articularis- on its cranial aspect with a saddlelike aspect, slightly excavated, as the negative of the surface described in malleus. The two facing surfaces are placed at an approximate angle of 60-70 degrees. The crura of the incus detach from the aboral part of the body of the ossicle. The short crus (Crus breve), conical and thicker at its base points in dorso-medial, oblique direction. The long crus (Crus longum) detach from the ventral border of the body to bend medially to continue with the lenticular process (Processus lenticularis). This process is cylindrically shaped, quite distinctive at the tip of the crus, with an oval articular surface for the junction with the head of stapes

The stapes (Stapes) is located in between the incus and the oval window. Almost triangular, with an oblique, ventro-medial and cranial disposition, it is composed of a head (Caput stapedis), dorsally placed, a base (Basis stapedis), ventro-medial and cranially placed linked by 2 crurae- the anterior crus (Crus rostrale) and the posterior crus (Crus caudale). The head is reduced, with a hemispherical articular 
surface for the lenticulate bone. Its caudal border bears a reduced tuberosity that serves as an insertion point for the stapedial muscle (m.stapedius)- the muscular process. The two crura, cylindrical and slightly divergent connect to the basal part of the bone. The posterior crus is thicker than the anterior one. The caudal border of the posterior crus seems concave while the anterior border is straight. The anterior crus, much thinner, presents a posterior border that is slightly concave while its anterior border is convex. This makes the anterior crus as being somehow curved as appearance while the posterior one seems quite straight. The base (footplate) of the stapes is elliptically shaped, with a medial surface that serves as attachment point to the oval window.

\section{Discussion}

The morphological aspects in case of the malleus in Capreollus capreollus are similar to those described in buffalo (Nourinezhad et al. 2021), donkeys (Nazih 2017), mice (Mohammadpour 2010) and even humans (Pracy et al. 1998). The oval aspect of the head of malleus was reported also in sheep (Simaei et al. 2017) and swine (Pracy et al. 1998) while in cavimorphs, moles and bovids (Argyle and Mason 2008; Simaei et al. 2017) these features are slightly different. The neck of the malleus shows the existence of three visible processes, opposite to the situation found in bovids and buffalo, where this segment is difficult to pinpoint (Nourinezhad et al. 2021). The three processes are noticeable in donkey (Nazih 2017; Gürbüz et al. 2019), rabbit (Kurtul et al. 2003), pig, and humans (Pracy et al. 1998). For the roe deer specimens a worth-mentioning aspect refers to the muscular process, which is evident and conicallyshaped (somehow similar to the situation described in buffalo (Nourinezhad et al. 2021)) while in donkey a reduced degree of development of this process is noted (Gürbüz et al. 2019).

The triangular shape of the handle of malleus appears different from the situation found in other ruminants- buffalo, cow and sheep (Nourinezhad et al. 2021).

The incus follows mostly the classical features of the bi radicular molar, with a shorter appearance at the level of the body of the incus. The lenticular process continues the long crus of the incus in medio-lateral direction. Similar facts were reported for goat ossicles (Martonos et al. 2021), dromedary camel (Nourinezhad et al. 2021), rabbit (Kurtul et al. 2003), rat (Li et al. 2015) and chinchilla (Martonos et al. 2019). This individualized piece of ossicle was also reported in some donkey individuals (Nazih 2017) and its absence was cited for sheep fetuses (Simaei et al. 2017)

The stapes is the smallest of the auditory ossicles. It is trapezoidal-shaped, similar to the features of the ossicle described in sheep (Nourinezhad et al. 2021), wolf (Gürbüz et al. 2019) and rabbit (Kurtul et al. 2003) while in other studied species, the ossicle is more like a rectangular piece- buffalo (Nourinezhad et al. 2021), cow (Costeur Loic et al. 2016) and pig (Pracy et al. 1998). Presence of the muscular process was also noted for other species like the donkey, bovids, rabbit, and wolf (Kurtul et al. 2003; Costeur Loic et al. 2016; Nazih 2017; Simaei et al. 2017; Gürbüz et al. 2019) while in humans and sheep fetuses it seems like the structure is just a small rough surface (Isaacson 2014; Simaei et al. 2017). The footplate of the stapes varies much as far as its shape is concerned from species to species. For the roe-deer, we 
have observed an elliptic shape, somehow similar to the bactrian camel (Bai et al. 2009; Nourinezhad et al. 2021), goat (Martonos et al. 2021), and chinchilla (Martonos et al. 2019). In sheep, this segment is described as almost squared (Nourinezhad et al. 2021).

The middle ear, in its morphology, can be regarded as a pressure amplifier. The ossicular arrangement, its joints, ligaments, and muscles do nothing but change the efficiency of the sound transmission (Huttenbrink 1992; Chhan et al. 2016) and generate mechanical advantage, from the tympanic membrane to the oval window towards the cochlear system (Uziel et al. 2009). The malleus and the incus can be regarded as a type 1 lever that has a counter-clock rotational movement as the tympanic membrane moves inward, pressing then against the internal crus of the stapes onto the oval window, with a cited ratio up to 19:1 effective tympanum to oval window (Pujol 1989). Another term used for the description of this assembly is "hinge-like rotational motion"(Péus et al. 2020) with leveraging capabilities. There is a direct relation between the surface area of the tympanic membrane, the surface of the footplate of the stapes, and the lever system of the middle ear, with a cited ratio between the two arms of the lever of aprox 1.3 (Uziel et al. 2009). By adopting this lever system to the actual measurements, mainly the ones that point to the elements forming the two arms of the lever, we can establish comparative data among related species that have available data (maleo-incal complex and stapes). More than that, some researchers suggest a complex calculation for the expected gain by this hinge-like rotation by multiplying the area ratio between the tympanic membrane (pars tensa) and oval window by the lever ratio of the malleo-incal complex.

A set of measurements (with different reference points) point us to a landmark that is usually not established morphologically but through CT and 3D volume reconstruction procedures- the establishment of the principal axes, the moments of inertia and the C.O.M (Center of mass)(Péus et al. 2020). Our approach did not use this kind of investigation, but due to the high resemblance to the sheep model that sources illustrated and cited, a similar point was established by using the three principal axes suggested (Péus et al. 2020).

To evaluate similarly the available data for the assessment of the lever ratio in the maleo-incal complex we have re-processed the data for sheep (Péus et al. 2017), goat (Martonos et al. 2021) along the ones from roe deer.The compared ratios are among the $L$ manu- $L$ mal, $L$ head- $L$ umbo (for malleus) and the incus the $L s p-L I p$ ratio. As suggested by the comparative figures calculated based on the two distinctive sets of measurements, some interesting facts arose here. The simple calculations of the total lengths of the malleus vs incus show some higher ratio for the goat ossicles, as the ones for sheep and roedeer are not so distant. Values for the length of the long crus of incus as opposed to the length of the stapes are showing higher values for goat, while the pair sheep-roe deer is similar. The malleus vs stapes total lengths are similar in all three compared sets of specimens.

In terms of the measurements used in the assessment of some functional ratios (Péus et al. 2020), a series of facts are revealed. Although the CenterOfMass point was an estimate in our approach for goat and roe deer samples, some figures are pointing to a much clearer differentiation of ratios in the case of 
the roe-deer data from the ones calculated for sheep and goats. This distinction may be a better indicator for the accuracy of the measurements taken in consideration in direct relation to the functional aspects that point to the mechanics of hearing in these species (lever ratios). Special attention is drawn towards the ratio of length of malleus and the length of the long crus of incus that shows a much smaller ratio for roe deer, as a possible differentiation that might be the result of another pattern in the transmission of vibrations along the complex system of the middle ear.

\section{Conclusions}

The present study brings into light some new elements of the middle ear anatomy for a species relatively little studied. This makes this main purpose of the study- the complete morphological description of the ear ossicles, alongside some morphometrical data. All these, combined, with series of graphical elements may serve as a useful didactical tool in the study of the comparative morphology of the middle ear and to point to some new directions in this study.

\section{Declarations}

\section{FUNDING}

The authors declare that no funds, grants, or other support were received during the preparation of this manuscript

\section{COMPETING INTERESTS}

The authors have no relevant financial or non-financial interests to disclose.

\section{Author contributions}

All authors contributed to the study concept and design. Material preparation, data collection and analysis were performed by Martonos Cristian and Gudea Alexandru. The first draft of the manuscript was written by Martonos Cristian and Gudea Alexandru. All authors commented on previous versions of the manuscript, read and approved the final version of this manuscript.

\section{Data availability}

The data that support the findings of this study are available from the corresponding author, Gudea Alexandru upon reasonable request.

\section{Ethics approval}

In line with the principles of the Declaration of Helsinki, the study was approved by the Committee of Bioethics and Research Ethics from the University of Agricultural Sciences and Veterinary Medicine ClujNapoca, Romania (188/04.12.2019). 


\section{Consent to participate}

This study did not involve human subjects or usage of biological material from humans.

\section{Consent for publication}

Not applicable

\section{References}

1. Argyle EC, Mason MJ (2008) Middle Ear Structures of Octodon degus (Rodentia: Octodontidae), in Comparison with Those of Subterranean Caviomorphs. J Mammal 89:1447-1455. https://doi.org/10.1644/07-mamm-a-401.1

2. Bai Z, Wang H, Yuan G et al (2009) A functional anatomy of the external and middle ear of the bactrian camel (Camelus bactrianus). J Camel Pract Res 16:115-120

3. Chhan D, Bowers P, McKinnon ML, Rosowski JJ (2016) Middle-ear and inner-ear contribution to bone conduction in chinchilla: The development of Carhart's notch. Hear Res. https://doi.org/10.1016/j.heares.2016.02.015

4. Costeur Loic, Mennecarta B, Muller B, Schulzb G (2016) Middle ear bones of a mid-gestation ruminant foetus extracted from X-ray computed tomography. Dev X-Ray Tomogr X

5. Gürbüz I, Demiraslan Y, Orhun Dayan M, Aslan K (2019) Morphometric and macroanatomic examination of auditory ossicles in male wolves (Canis lupus). Folia Morphol 78:600-605. https://doi.org/10.5603/FM.a2019.0011

6. Huttenbrink KB (1992) The mechanics and the function of the middle-ear. Part 1: Normal ossicular chain and middle-ear muscles. Laryngorhinootologie 71:545-551

7. Isaacson G (2014) Endoscopic Anatomy of the Pediatric Middle Ear. Otolaryngol Neck Surg 150:615. https://doi.org/10.1177/0194599813509589

8. Kurtul I, Cevik A, Bozkurt EU, Dursun N (2003) A detailed subgross morphometric study on the auditory ossicles of the New Zealand rabbit. J Vet Med Ser C Anat Histol Embryol 32:249-252. https://doi.org/10.1046/j.1439-0264.2003.00483.x

9. Li P, Gao K, Ding D, Salvi R (2015) Characteristic anatomical structures of rat temporal bone. J Otol 10:118-124. https://doi.org/10.1016/j.joto.2015.11.002

10. Martonos C, Damian A, Gudea A et al (2019) Morphological and morphometrical study of the auditory ossicles in chinchilla. Anat Histol Embryol 48:340-345. https://doi.org/10.1111/ahe.12446

11. Martonos CO, Gudea A, Damian A et al (2021) Morphological and morphometrical aspects of the auditory ossicles in goat (Capra hircus). J Vet Med Ser C Anat Histol Embryol 50:184-191. https://doi.org/10.1111/ahe.12617

12. Mason M, Farr M (2012) Flexibility within the middle ears of vertebrates. J Laryngol Otol 127:1-13. https://doi.org/10.1017/S0022215112002496 
13. Mohammadpour AA (2010) Morphological study of auditory ossicles in the mouse. J Appl Anim Res 37:269-271. https://doi.org/10.1080/09712119.2010.9707139

14. Nazih AM (2017) Anatomical Study on the Middle Ear of Donkey (Equus acinus). Int J Adv Res Biol Sci 4:110-121. https://doi.org/10.22192/ijarbs.2017.04.08.016

15. Nourinezhad J, Abedini M, Shamsi MM et al (2021) Evaluation of the middle ear in water buffaloes (Bubalus bubalis) by gross anatomy and cone-beam computed tomography. Folia Morphol (Warsz) 80:177-185. https://doi.org/10.5603/FM.A2020.0036

16. Péus D, Dobrev I, Pfiffner F, Sim JH (2020) Comparison of sheep and human middle-ear ossicles: anatomy and inertial properties. J Comp Physiol A 206:683-700. https://doi.org/10.1007/s00359020-01430-w

17. Péus D, Dobrev I, Prochazka L et al (2017) Sheep as a large animal ear model: Middle-ear ossicular velocities and intracochlear sound pressure. Hear Res 351. https://doi.org/10.1016/j.heares.2017.06.002

18. Pfaff C, Schultz JA, Schellhorn R (2019) The vertebrate middle and inner ear: A short overview. J Morphol 280:1098-1105

19. Pracy JP, White A, Mustafa Y et al (1998) The Comparative Anatomy of the Pig Middle Ear Cavity: A Model for Middle Ear Inflammation in the Human? J Anat 192:359-368. https://doi.org/10.1046/J.1469-7580.1998.19230359.X

20. Pujol R (1989) Anatomie et physiologie de la cochlée. Arch Physiol Biochem 97:51-78. https://doi.org/10.3109/13813458909105536

21. Simaei N, Soltanalinejad F, Najafı G, Shalizar Jalali A (2017) Anatomical and Morphometrical Study of Middle Ear Ossicles in 2 to 3-Month-old Makouei Sheep Fetuses. Vet Res forum an Int Q J 8:237241

22. Uziel A, Marot M, Pujol R (2009) The Gunn Rat: An Experimental Model for Central Deafness. http://dx.doi.org/103109/00016488309139458 95:651-656. https://doi.org/10.3109/00016488309139458

23. Wang X, Gan RZ (2016) 3D finite element model of the chinchilla ear for characterizing middle ear functions. Biomech Model Mechanobiol 15:1263-1277. https://doi.org/10.1007/s10237-016-0758-5

\section{Tables}

\section{Tabe 1. Basic measurements for the auditory ossicles}




\section{Malleus}

\begin{tabular}{lll}
\hline$L M$ & 6.43 & 7 \\
\hline$L H M$ & 1.55 & 6 \\
\hline$W H D^{*}$ & 1.16 & 5 \\
(not to include the bony lamellae) & & \\
\hline LHM & 3.91 & 8 \\
\hline Incus & & \\
\hline$W B I$ & 1.50 & 6 \\
\hline$H B I$ & 1.64 & 5 \\
\hline$L S C$ & 3.17 & 4 \\
\hline$L L C$ & 1.58 & 5 \\
\hline$L I$ & 3.19 & 5 \\
\hline
\end{tabular}

\section{Stapes}

\begin{tabular}{lll}
$W B S$ & 1.63 & 8 \\
\hline$L C C$ & 1.94 & 7 \\
\hline$L R C$ & 1.85 & 9 \\
\hline$W H S$ & 0.91 & 5 \\
\hline$L S$ & 1.93 & 8
\end{tabular}

\section{Supplementary measurements Malleus}

\begin{tabular}{lll}
\hline L mal & 6.52 & 4 \\
\hline$L$ manu & 4.08 & 6 \\
\hline$L$ umbo & 4.91 & 3 \\
\hline$L$ head & 2.30 & 5 \\
\hline Incus & & \\
\hline$L s p$ & 2.11 & 2 \\
\hline$L I p$ & 1.93 & 5
\end{tabular}

LM- length of malleus, LHM- length of the head of malleus, WDH-width of the head of mallei, LHM- length of the head of mallei, WBI-width of the body of incudes, HBI-height of the body of incudes, LSC-length of 
the short crus, LLC- length of the long crus, LI-length of incus, WBS-width of the base of the stapes, LCClength of the caudal crus, LRC- length of the rostral crus, WHS-width of the head of the stapes, LS-Length of the stapes

\section{Supplementary measurements for the auditory ossicles}

$L$ mal- length of malleus; $L$ manu- the manubrium length, $L$ umbo-tip umbo of malleus to CenterOfMass (estimated), $L$ head-CenterOfMass to tip of malleus

$L$ sp-length of the short process; LIp-length of the long process (as measured from CenterOfMass (estimated.

Table 2. Comparative measurements and ratios of the auditory ossicles in sheep, goat and roe-deer using measurements suggested by Peus (2017)

\begin{tabular}{llll} 
Measurements & Ovis & Capra & Capreollus \\
\hline L maleus & 7,88 & 8,16 & 6,48 \\
\hline L Ic & 1,67 & 1,46 & 1,58 \\
\hline H stapes & 2,1 & 2,79 & 1,93 \\
\hline Ratio maleus/incus & 4,72 & 5,59 & 4,10 \\
\hline Ratio maleus/stapes & 0,27 & 0,34 & 0,30 \\
\hline Ratio L Ic/H stapes & 1,26 & 1,91 & 1,22 \\
\hline & & & \\
\hline L manu & 5,26 & 6,32 & 4,14 \\
\hline L mal & 7,88 & 9,6 & 6,65 \\
\hline L head & 2,96 & 3,23 & 2,33 \\
\hline L umbo & 5,32 & 6,83 & 4,94 \\
\hline L sp & 2,52 & 2,15 & 2,07 \\
\hline L Ip & 1,67 & 1,48 & 2,01 \\
\hline Ratio L manu:L mal & 0,67 & 0,66 & 0,62 \\
\hline Ratio L head-L umbo & 0,56 & 0,47 & 0,47 \\
\hline Ratio L sp:L Ip & 1,52 & 1,45 & 1,03 \\
\hline Ratio L mal:L Ip & 4,72 & 5,51 & 3,22 \\
\hline
\end{tabular}



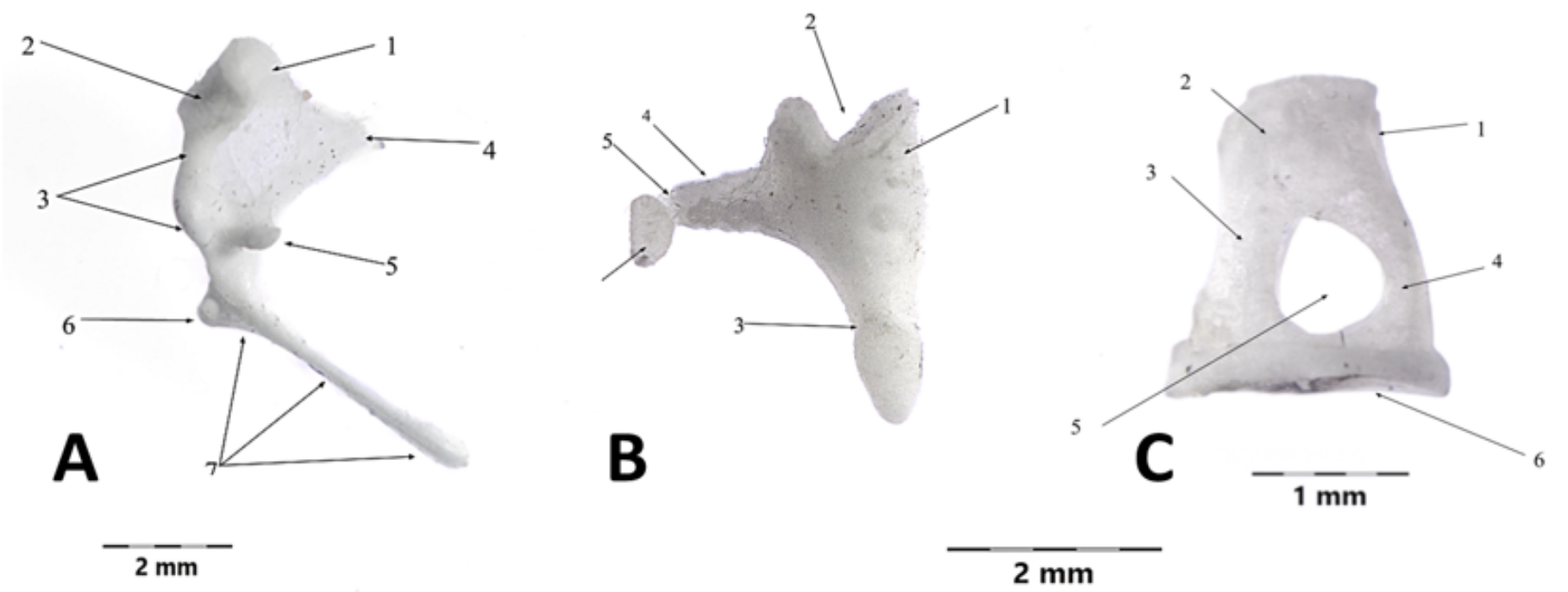

\section{Figure 1}

\section{The auditory ossicles in roe deer (native specimens)}

A. Malleus 1-Caput mallei, 2-Facies articularis, 3-Collum mallei, 4-Processus rostralis, 5-Processus muscularis, 6-Processus lateralis, 7-Manubrium mallei

B. Incus 1-Corpus incudes, 2-Processus articularis, 3-Crus breve, 4-Crus longum, 5-Processus lenticularis, 6-Facies articularis os stapedius

C. Stapes 1-Caput stapedis, 2-Tuber m.stapedius, 3-Crus rostrale, 4-Crus caudale, 5-Intercrusal foramen, 6-Basis stapedis 